\title{
A Study of Dentists about Their Knowledge and Practice of Dentine Hypersensitivity
}

\author{
${ }^{1}$ Department of Community and Preventive Dentistry, FMH College \\ of Medicine \& Dentistry, Lahore, Pakistan \\ 2Department of Preventive Dental Sciences, College of Dentistry, \\ Imam Abdulrahman Bin Faisal University, Dammam, Saudi Arabia \\ ${ }^{3}$ Department of Restorative Dental Science, College of Dentistry, \\ Imam Abdulrahman Bin Faisal University, Dammam, Saudi Arabia \\ Eur J Dent 2019;13:540-546
}

Faisal Izhar ${ }^{1}$ Muhammad Ashraf Nazir ${ }^{2} \quad$ Abdul Majeed $^{3} \quad$ Khalid Almas $^{2}$

Address for correspondence Muhammad Ashraf Nazir, BSc, BDS, MPH, FRSPH, Department of Preventive Dental Sciences, College of Dentistry, Imam Abdulrahman Bin Faisal University, Dammam, P. O. Box 1982, Dammam 31441, Saudi Arabia (e-mail: manazir@iau.edu.sa).

\begin{abstract}
Objective The aim of this study was to evaluate the knowledge and practice about dentine hypersensitivity $(\mathrm{DH})$ among dental practitioners.

Materials and Methods A pilot-tested questionnaire was sent to practicing dentists $(n=588)$ working in private and public sectors in Lahore, Pakistan. The questions assessed dentists' knowledge about type of pain and predisposing factors of $\mathrm{DH}$. The dentists were asked about their preferred methods of diagnosing and managing the condition.

Statistical Analysis Basic statistics, chi-squared test, and multivariate logistic regression were performed.

Results Most dentists (64.3\%) reported examining one to five patients with $\mathrm{DH}$ per week in their dental clinics. A large majority $(85.4 \%)$ indicated DH as a stimulated short pain from a tooth. Recession of gums (96.6\%), aggressive brushing (88.2\%), and frequent use of teeth whitening procedures $(83.1 \%)$ were most frequently reported predisposing factors of $\mathrm{DH}$. Among most commonly used methods of diagnosis, spontaneous pain after the application of air blast was reported by $74.8 \%$ of the participants and followed by spontaneous patient report confirmed by dental examination (57.7\%). Most widely used management approaches of $\mathrm{DH}$ included the use of fluoride

Keywords

- dentine hypersensitivity

- dentists

- knowledge

- diagnosis

- management products (96.2\%), use of desensitizing potassium nitrate toothpastes (75\%), and application of bonding agents (56.2\%). Female versus male dentists (odds ratio [OR]: 7.79, $p<0.001$ ) and private practitioners versus public dentists (OR: $7.34, p<0.001$ ) were more likely to examine greater number of patients with $\mathrm{DH}$.

Conclusion Dentists used various methods for diagnosing and managing patients with $\mathrm{DH}$. Application of air blast to evaluate spontaneous pain and use of fluoride products were most widely used diagnostic and management preferences, respectively.
\end{abstract}

\section{Introduction}

Dentine hypersensitivity (DH) is a common oral condition that is characterized by sharp and transient pain frequently arising from thermal, chemical, tactile stimuli in exposed dentine. ${ }^{1}$ Stimulation resulting from cold food or drink is the most common cause of pain; however, the use of citrus fruits, sweets, and salty food can also lead to $\mathrm{DH} .^{2}$
Discomfort associated with DH negatively affects the quality of life of patients. ${ }^{3,4}$ Patients with DH avoid eating, drinking and brushing, and consult dentist or use self-medication to relive the pain. ${ }^{5}$ Gingival recession, excessive tooth brushing, scaling and root planning, and attrition are some of the common predisposing factors of DH. ${ }^{6}$ Previous studies reported the prevalence of DH in different parts of the world that ranged from 20.6 to $41.9 \% .^{5-10}$ However, a study of patients 
attending a teaching dental hospital documented a prevalence of $1.34 \%{ }^{11}$

It was reported that the majority of dentists were aware of the etiological factors of DH in United Kingdom. ${ }^{12}$ Most of Australian dentists reported understanding of $\mathrm{DH}$ and prescribed desensitizing agents to treat the condition. ${ }^{13}$ According to dental practitioners in the United States, the use of desensitizing potassium nitrate toothpaste was the most common treatment modality for the management of $\mathrm{DH} .{ }^{14}$ Similarly, dentists in the United States identified gingival recession, abrasion, erosion, and attrition as the most common predisposing factors of $\mathrm{DH}$ and employed a variety of diagnostic methods. ${ }^{2}$ The most common theories of $\mathrm{DH}$ include direct innervation theory, odontoblast receptor theory, and fluid movement/hydrodynamic theory.${ }^{15}$ About half the Nigerian dentists correctly identified "hydrodynamic theory" as the most common theory of $\mathrm{DH}^{15}$ and had inadequate knowledge and skills to diagnose and manage the condition. ${ }^{16}$

DH is highly prevalent and underdiagnosed condition that can be treated with a wide variety of inexpensive medications. ${ }^{1}$ Hence, adequate understanding of DH among dentists is critical for the successful treatment of the condition to improve the standard of care and quality of life of patients. There is a lack of reliable data about DH among dentists in Pakistan. The objective of the study was to assess dentists' knowledge and practice of DH in Lahore, Pakistan.

\section{Materials and Methods}

This is a cross-sectional observation study. The target population was practicing dentist from private and public sectors in Lahore, Pakistan. The dentists with more than one year of clinical experience, practicing in Lahore, and those who showed voluntary participation met eligibility criteria for the selection in the present study. The study was conducted from October 2017 to December 2017 with a calculated sample of 588 eligible dentists. A 95\% confidence interval, anticipated percentage frequency, and estimated population size were used for sample size calculation. ${ }^{17}$ The power of study was $80 \%$ assuming $\beta$ equal to 0.20 (power $=1-\beta$ ).

A questionnaire was developed based on previous similar studies. ${ }^{2,12-16}$ The self-administered structured questionnaire had closed ended questions about sociodemographic data/ knowledge and diagnosis/management of $\mathrm{DH}$. The instrument was piloted over 30 participants to evaluate its applicability and practicality in the field. Modifications were made based on the results of the pilot study. For example, there were seven options against the question about the number of patients complaining of $\mathrm{DH}$. These options were reduced to four after dentists' feedback. Finally, approved questionnaire was administered among dentists in their clinics. For the purpose of obtaining satisfactory response rate, research assistants made maximum of three visits to dental clinics to accommodate the busy schedule of the dentists.

Ethical approval was obtained from the Institutional Review Board at the Fatima Jinnah Medical and Dental College, Lahore. The study participants provided their consents by filling out the questionnaire. The researchers briefed participants through one-on-one discussion about the details of study including the objective and purpose of study. Identification of study participants remained concealed because of anonymous questionnaire. The study was conducted in full accordance with the World Medical Association Declaration of Helsinki.

Descriptive statistics were expressed using frequency distribution, mean, and standard deviation. Pearson's chisquared tests were performed to evaluate the relationship of independent variables with knowledge, diagnosis, and management of $\mathrm{DH}$. In addition, examination of number of patients with DH per week was used as the dependent variable and was dichotomized in to those who examined 0 to 10 patients (lesser number of patients) and 11 to $\geq 20$ patients (greater number of patients) per week. Gender, type of job, monthly income, year since graduation, and basic dental qualifications were used as covariates to evaluate their influence on examining greater number of patients with $\mathrm{DH}$ per week and crude and adjusted odds ratio [OR]: were calculated with $95 \%$ confidence interval. For statistical tests, $p$-value was set at $<0.05$. Statistical analyses were performed using SPSS software (IBM SPSS Statistics for Windows, Version 22.0. Armonk, New York, United States).

\section{Results}

The study had a good response rate (89.6\%, 527/588 dentists). The study sample comprised of $41.6 \%$ of male and $58.4 \%$ of female dentists. The mean age of the participants was 29.46 \pm 3.04 years. Almost half the participants (46.1\%) were from private dental practice and $47.1 \%$ obtained their basic dental qualification from a private dental institution. Similarly, about half the participants (56\%) had $\leq 5$ years since graduation. The majority (64.3\%) reported examining one to five patients with DH per week in their dental clinics (-Table 1).

Regarding the type of pain in $\mathrm{DH}$, stimulated short pain from a tooth was the most common (85.4\%) and it significantly differed between male (49.8\%) and female dentists $(50.2 \%)(p<0.001)$. Recession of gums (96.6\%), aggressive brushing $(88.2 \%)$, and frequent use of tooth whitening procedures $(83.1 \%)$ were the most common predisposing factors of $\mathrm{DH}$. Significantly greater percentage of male (55.6\%) than female $(44.4 \%)$ dentists considered recession of gums as a predisposing factor of $\mathrm{DH}(p<0.001)$. Similarly, more male (55.7\%) than female participants $(44.3 \%)$ believed that DH is caused by aggressive brushing $(p<0.012)$. In contrast, more female (55.7\%) than male dentists (44.3\%) identified frequent use of teeth whitening procedures as a predisposing factor of DH $(p<0.001)$ ( - Table 2).

Among diagnostic methods, the participants most frequently reported evaluating spontaneous pain after the application of air blast (74.8\%), followed by spontaneous patient report confirmed by dental examination (57.7\%) and spontaneous pain after the application of cold water (43.3\%). The electric pulp tester was used by only two dental practitioners in the study. Significantly, higher percent of female versus male dentists preferred diagnosing $\mathrm{DH}$ by spontaneous pain after the application of air blast and cold water 
Table 1 Distribution of responses of dentists

\begin{tabular}{|c|c|}
\hline Variables & $n(\%)$ \\
\hline \multicolumn{2}{|l|}{ Gender } \\
\hline Male & $219(41.6)$ \\
\hline Female & $308(58.4)$ \\
\hline \multicolumn{2}{|l|}{ Type of job } \\
\hline Private & $243(46.1)$ \\
\hline Public & $284(53.9)$ \\
\hline \multicolumn{2}{|c|}{ Basic dental qualification obtained from } \\
\hline Private institution & $248(47.1)$ \\
\hline Public institution & $279(52.9)$ \\
\hline \multicolumn{2}{|l|}{ Year since graduation } \\
\hline$\leq$ Five years & $295(56)$ \\
\hline >Five years & $232(44)$ \\
\hline \multicolumn{2}{|l|}{ Monthly income } \\
\hline$<500$ \$US & $219(41.6)$ \\
\hline$\geq 500 \$$ US & $308(58.4)$ \\
\hline \multicolumn{2}{|c|}{ Number of patients with DH per week } \\
\hline 1-5 patients per week & $339(64.3)$ \\
\hline 6-10 patients per week & $81(15.4)$ \\
\hline 11-15 patients per week & 89 (16.9) \\
\hline $16-\geq 20$ patients per week & $18(3.4)$ \\
\hline Age & $\begin{array}{l}\text { Mean } \pm \text { SD } \\
29.46 \pm 3.04\end{array}$ \\
\hline
\end{tabular}

Abbreviation: $\mathrm{DH}$, dentine hypersensitivity. $(p<0.001)(-$ Table 3$)$. The use of fluoride products was the most frequently $(96.2 \%)$ reported management approach of DH followed by potassium nitrate toothpastes (75\%) and dentine bonding agents (56.2\%). Significantly higher percentage of male dentists preferred using these products compared with female dentists $(p<0.001)$. Glutaraldehyde/HEMA products $(8.2 \%)$ and oxalates $(8.7 \%)$ were the least commonly employed methods for the management of $\mathrm{DH}(-$ Table 3 ).

- Table 4 summarizes data about the comparison between private and public dentists, and dentists with $\leq 5$ year since graduation and those with $>5$ years since graduation with regard to their preferences for diagnosis and management of $\mathrm{DH}$. The use of air blast and cold water was more frequently employed by public dentists and dentists with more experience ( $>5$ years) than private dentists and dentists with less experience $(\leq 5$ year) since graduation $(p<0.001)$. Significantly higher proportion of public dentists (56\%) used fluoride products than private practitioners $(44 \%)(p<0.001)$. However, no significant differences were observed regarding the use of potassium nitrate toothpaste between private and public dentists $(p=0.667)$. The dentist with $\leq 5$ years of experience $(58.2 \%$ ) used fluoride products, dentine bonding agents, and diet counseling more commonly than those with $>5$ years of experience $(41.8 \%)(p<0.001)$ ( - Table 4$)$. Multivariate logistic regression analysis demonstrated that female dentists (OR: $7.79, p<0.001$ ), private practitioners (OR: 7.34, $p<0.001$ ), and dentists with monthly income of $\geq 500$ \$US per month (OR: 9.41, $p<0.001)$ were more likely to examine greater number of patients with DH. Similarly, the odds of examining greater number of patients with DH per week

Table 2 Knowledge of male and female dentists about dentine hypersensitivity

\begin{tabular}{|c|c|c|c|c|}
\hline Response & Sample $n / \%$ & Male $n / \%$ & Female $n / \%$ & $p$-Value \\
\hline \multicolumn{5}{|l|}{ Types of pain in DH } \\
\hline Spontaneous throbbing pain from a tooth & $2(0.4)$ & $0(0)$ & $2(100)$ & 0.127 \\
\hline Intermittent short sharp pain from a tooth & $149(28.3)$ & $137(91.9)$ & $12(8.1)$ & $<0.001$ \\
\hline Stimulated short sharp pain from a tooth & $450(85.4)$ & $224(49.8)$ & $226(50.2)$ & $<0.001$ \\
\hline Chronic dull pain from a tooth & $56(10.6)$ & $0(0)$ & $56(100)$ & $<0.001$ \\
\hline \multicolumn{5}{|l|}{ Predisposing factors of DH } \\
\hline Aggressive brushing /over brushing & $465(88.2)$ & $259(55.7)$ & $206(44.3)$ & 0.012 \\
\hline Frequent use of teeth whitening procedures & $438(83.1)$ & $194(44.3)$ & $244(55.7)$ & $<0.001$ \\
\hline Excessive dental flossing & $35(6.6)$ & $35(100)$ & $0(0)$ & $<0.001$ \\
\hline Recession of gingiva & 509 (96.6) & $283(55.6)$ & $226(44.4)$ & $<0.001$ \\
\hline Periodontal surgery & $96(18.2)$ & $44(45.8)$ & $52(54.2)$ & 0.087 \\
\hline Scaling and root planning & $398(75.5)$ & $257(64.6)$ & $141(35.4)$ & $<0.001$ \\
\hline Periodontal pocket & $192(36.4)$ & $89(46.4)$ & $103(53.6)$ & 0.010 \\
\hline Bruxism & $218(41.4)$ & $160(73.4)$ & $58(26.6)$ & $<0.001$ \\
\hline Smoking & $2(0.4)$ & 2 & 0 & 0.188 \\
\hline Abrasion, erosion, abfraction and/or attrition & $403(76.5)$ & $224(55.6)$ & $179(44.4)$ & 0.118 \\
\hline Excessive use of citrus juices, and/or carbonated drinks & 337 (63.9) & $196(58.2)$ & $141(41.8)$ & 0.006 \\
\hline Gastric reflux and/or excessive vomiting & $287(54.5)$ & $196(68.3)$ & $91(31.7)$ & $<0.001$ \\
\hline Trauma during tooth preparation & $383(72.7)$ & $256(66.8)$ & $127(33.2)$ & $<0.001$ \\
\hline Loss of cementum & $394(74.8)$ & $246(62.4)$ & $148(37.6)$ & $<0.001$ \\
\hline
\end{tabular}

Abbreviation: $\mathrm{DH}$, dentine hypersensitivity. 
Table 3 Practice of male and female dentists about the diagnosis of dentine hypersensitivity

\begin{tabular}{|c|c|c|c|c|}
\hline Diagnostic methods of DH & Sample $n / \%$ & Male $n / \%$ & Female $n / \%$ & $p$-Value \\
\hline Spontaneous patient report confirmed by dental exam & $304(57.7)$ & $105(53.8)$ & $90(46.2)$ & 0.959 \\
\hline Patient report after dentist's query & $195(37)$ & $206(52.3)$ & $188(47.7)$ & 0.262 \\
\hline Spontaneous pain after the application of air blast & $394(74.8)$ & $99(43.4)$ & $129(56.6)$ & $<0.001$ \\
\hline Spontaneous pain after the application of cold water & $228(43.3)$ & $99(43.4)$ & $129(56.6)$ & $<0.001$ \\
\hline Spontaneous pain after scratching dentine with dental explorer & $181(34.3)$ & $106(58.6)$ & $75(41.4)$ & 0.105 \\
\hline Use of electric pulp tester & $2(0.4)$ & 2 & 0 & 0.188 \\
\hline Asking patient to numerically rate pain & $97(18.4)$ & $41(42.3)$ & $56(57.7)$ & 0.012 \\
\hline Asking patient to rate pain using visual analogue scale & $79(15)$ & 0 & 75 & $<0.001$ \\
\hline \multicolumn{5}{|l|}{ Management preferences of DH } \\
\hline Use of fluoride products (e.g., gels, varnishes, pastes, rinses) & $507(96.2)$ & $283(55.8)$ & $224(44.2)$ & $<0.001$ \\
\hline Use of desensitizing potassium nitrate toothpastes & $395(75)$ & $247(62.5)$ & $148(37.5)$ & $<0.001$ \\
\hline Application of glutaraldehyde/HEMA products & $43(8.2)$ & $43(100)$ & $0(0)$ & $<0.001$ \\
\hline Application of dentine bonding agents & $296(56.2)$ & $180(60.8)$ & $116(39.2)$ & $<0.001$ \\
\hline Application of sealants & $120(22.8)$ & $4(3.3)$ & $116(96.7)$ & $<0.001$ \\
\hline Provision of restorative treatments & $180(34.2)$ & $128(71.1)$ & $52(28.9)$ & $<0.001$ \\
\hline Use of lasers & $56(10.6)$ & $2(3.6)$ & $54(96.4)$ & $<0.001$ \\
\hline Use of oxalates & $46(8.7)$ & 28 (60.9) & $18(39.1)$ & 0.307 \\
\hline Diet counseling & $290(55)$ & 165 (56.9) & $125(43.1)$ & 0.104 \\
\hline
\end{tabular}

Abbreviation: $\mathrm{DH}$, dentine hypersensitivity.

were significantly higher for dentists with $\geq 5$ years since graduation (OR: 2.75, $p=0.002$ ) and those who obtained basic dental qualification from private dental institution (OR: 2.04, $p=0.026)$ (-Table 5).

\section{Discussion}

This study evaluated dentists' preferences about the diagnosis and management of DH in addition to their understanding about the type of pain and its predisposing factors. In line with the results of a previous study (92.8\%) in Nigeria, ${ }^{16} \mathrm{a}$ vast majority of participants (85.4\%) in this study described $\mathrm{DH}$ as a stimulated short sharp pain. It is known that $\mathrm{DH}$ is a multifactorial condition. ${ }^{10,18}$ The present study showed that dental practitioners identified different etiological factors leading to $\mathrm{DH}$; however, gingival recession was the most frequently reported factor. This finding is in accordance with similar questionnaire-based studies of dental practitioners in the United.States and Australia., ${ }^{2,13}$ On the other hand, Indian dentists indicated dental caries as the main etiological agent of $\mathrm{DH}^{19}{ }^{19}$ The finding of gingival recession as the most common etiological factor is supported by one of the most widely accepted theories of $\mathrm{DH}$, hydrodynamic theory. ${ }^{5}$ Clinical studies from China, India, and Brazil had also reported an association between gingival recession and $\mathrm{DH}^{7,8,10}$

Dental practitioners in our study used diverse diagnostic methods; however, they most frequently used air blast to evaluate the spontaneous pain of $\mathrm{DH}$, followed by spontaneous patient report confirmed by dental exam. Similarly, dentists in the United States most frequently diagnosed DH by confirming patient report coupled with clinical examination, while air blast was the second most commonly used method of diagnosis. ${ }^{2}$ Another study in the United States also reported that most dental practitioners relied on patients' report for the diagnosis of $\mathrm{DH} .{ }^{20}$ In Senegal, 68\% of dentists used mechanical stimuli to diagnose the DH pain. ${ }^{21}$ Scratching of tooth was the most commonly used diagnostic method reported by dentists in Nigeria. ${ }^{16}$

The current study found that many different diagnostic techniques of DH differed significantly between male and female dentists, private and public dentists, and dentists with lesser and greater clinical experience. However, consistent patterns regarding the use of diagnostic methods among these dentists were not identified in the study. The present study demonstrated that the use of fluoride formulations and potassium nitrate toothpaste was the most common preferences for the management of $\mathrm{DH}$. These findings are in agreement with the results of previous studies in Canada, United Kingdom, Australia, and the United States. ${ }^{2,12,13,20}$ A recent study of private practitioners in India reported the prescription of desensitizing agents for home use as the most common management option. ${ }^{19}$ Recently, dentists used sensitivity toothpastes and desensitizers as the most frequently recommended first line of treatment of DH in United Kingdom. ${ }^{22}$ It was also found that the application of fluoride toothpaste resulted in improved satisfaction of patients with the treatment of $\mathrm{DH}^{23}$ In addition, striking similarities were observed between dentists' preferences for the treatment of $\mathrm{DH}$ and actual recommendations for patients with $\mathrm{DH} .{ }^{2,14}$

The use of dentine bonding agent (56.2\%) and diet counseling (55\%) were the third most common treatment modalities in this study. These findings are consistent with the 
Table 4 Practice of private and public dentists and dentists with $\leq 5$ and $>5$ years of experience about the management of dentine hypersensitivity

\begin{tabular}{|c|c|c|c|c|c|c|}
\hline Diagnostic methods of DH & $\begin{array}{l}\text { Private } \\
\text { practitioners }\end{array}$ & $\begin{array}{l}\text { Public } \\
\text { dentist }\end{array}$ & $p$-Value & $\begin{array}{l}\text { Dentist with } \\
\leq 5 \text { years since } \\
\text { graduation }\end{array}$ & $\begin{array}{l}\text { Dentist with } \\
>5 \text { years since } \\
\text { graduation }\end{array}$ & $p$-Value \\
\hline $\begin{array}{l}\text { Spontaneous patient report con- } \\
\text { firmed by dental exam }\end{array}$ & $141(46.4)$ & $\begin{array}{l}163 \\
(53.6)\end{array}$ & 0.884 & $179(58.9)$ & $125(41.1)$ & 0.117 \\
\hline Patient report after dentist's query & $80(41)$ & $115(59)$ & 0.073 & $157(80.5)$ & $38(19.5)$ & $<0.001$ \\
\hline $\begin{array}{l}\text { Spontaneous pain after the applica- } \\
\text { tion of air blast }\end{array}$ & $147(37.3)$ & $\begin{array}{l}247 \\
(62.7)\end{array}$ & $<0.001$ & $182(46.2)$ & $212(53.8)$ & $<0.001$ \\
\hline $\begin{array}{l}\text { Spontaneous pain after the applica- } \\
\text { tion of cold water }\end{array}$ & $58(25.4)$ & $\begin{array}{l}170 \\
(74.6)\end{array}$ & $<0.001$ & $74(32.5)$ & $154(67.5)$ & $<0.001$ \\
\hline $\begin{array}{l}\text { Spontaneous pain after scratching } \\
\text { dentine with dental explorer }\end{array}$ & $82(45.3)$ & $\begin{array}{l}99 \\
(54.7)\end{array}$ & 0.788 & $76(42)$ & $105(58)$ & $<0.001$ \\
\hline Use of electric pulp tester & $2(100)$ & $0(0.0)$ & $0.212^{\mathrm{a}}$ & $2(100)$ & $0(0.0)$ & $0.506^{\mathrm{a}}$ \\
\hline $\begin{array}{l}\text { Asking patient to numerically rate } \\
\text { pain }\end{array}$ & 95 (97.9) & $2(2.1)$ & $<0.001$ & $36(37.1)$ & $61(62.9)$ & $<0.001$ \\
\hline $\begin{array}{l}\text { Asking patient to rate pain using } \\
\text { visual analogue scale }\end{array}$ & $41(51.9)$ & $\begin{array}{l}38 \\
(48.1)\end{array}$ & 0.263 & $61(77.2)$ & $18(22.8)$ & $<0.001$ \\
\hline \multicolumn{7}{|l|}{ Management preferences of $\mathrm{DH}$} \\
\hline $\begin{array}{l}\text { Use of fluoride products (e.g., gels, } \\
\text { varnishes, pastes, rinses) }\end{array}$ & $223(44)$ & $284(56)$ & $<0.001$ & $295(58.2)$ & $212(41.8)$ & $<0.001$ \\
\hline $\begin{array}{l}\text { Use of desensitizing potassium nitrate } \\
\text { toothpastes }\end{array}$ & $180(45.6)$ & $\begin{array}{l}215 \\
(54.4)\end{array}$ & 0.667 & $232(58.7)$ & $163(41.3)$ & 0.027 \\
\hline $\begin{array}{l}\text { Application of glutaraldehyde/HEMA } \\
\text { products }\end{array}$ & $43(100)$ & $0(0)$ & $<0.001$ & $2(4.7)$ & $41(95.3)$ & $<0.001$ \\
\hline $\begin{array}{l}\text { Application of dentine bonding } \\
\text { agents }\end{array}$ & $166(56.1)$ & $\begin{array}{l}130 \\
(43.9)\end{array}$ & $<0.001$ & $140(47.3)$ & $156(52.7)$ & $<0.001$ \\
\hline Application of sealants & $85(70.8)$ & $\begin{array}{l}35 \\
(29.2)\end{array}$ & $<0.001$ & $65(54.2)$ & $55(45.8)$ & 0.649 \\
\hline Provision of restorative treatments & $5(2.8)$ & $\begin{array}{l}175 \\
(97.2)\end{array}$ & $<0.001$ & $77(42.8)$ & $103(57.2)$ & $<0.001$ \\
\hline Use of lasers & $56(100)$ & $0(0)$ & $<0.001$ & $38(67.9)$ & $18(32.1)$ & 0.058 \\
\hline Use of oxalates & $20(43.5)$ & $\begin{array}{l}26 \\
(56.5)\end{array}$ & 0.708 & $2(4.3)$ & $44(95.7)$ & $<0.001$ \\
\hline Diet counseling & $97(33.4)$ & $\begin{array}{l}193 \\
(66.6)\end{array}$ & $<0.001$ & $151(52.1)$ & $139(47.9)$ & 0.046 \\
\hline
\end{tabular}

Abbreviation: $\mathrm{DH}$, dentine hypersensitivity.

aFisher's exact test.

results of a previous study. ${ }^{20}$ It is known that dietary acids can cause erosion of enamel, leading to the exposure of dentine and dentinal tubules that results in increased flow of fluids upon stimulation. ${ }^{6}$ The use of bonding agent can significantly reduce symptoms of $\mathrm{DH}^{24}$ This might explain why almost half the dentists in our study reported using bonding agent and providing dietary counseling for the treatment of $\mathrm{DH}$.

The application of glutaraldehyde/HEMA products (8.2\%) and use of oxalates $(8.7 \%$ ) were the least frequently reported treatment modalities in the present study. This is in contrast to the findings of a previous study which found that $58 \%$ and $46 \%$ of participating dentists used glutaraldehyde/HEMA products and oxalates, respectively. ${ }^{20}$ The effectiveness of laser for the treatment of DH has been demonstrated in many clinical studies. ${ }^{25-27}$ Despite, only $10.6 \%$ of dentists preferred lasers for the management of DH in the current study, possibly because most dentists might not afford laser apparatus in their clinics.

The results of this study showed inconsistent trends regarding treatment modalities among dentists. It was found that significantly higher percent of male than female dentists used fluorides products, desensitizing potassium nitrates toothpastes, and application of bonding agents to manage DH. On the contrary, male and female dentists showed no significant differences about providing diet counseling. Similarly, more public dentists used fluoride products and provided diet counseling than private practitioners. However, no significant differences were observed regarding the use of potassium nitrate toothpaste between private and public dentists. 
Table 5 Bivariate and multivariate logistic regression: Factors associated with the examining of greater number of patients with dentin hypersensitivity

\begin{tabular}{|c|c|c|c|c|}
\hline \multirow[t]{2}{*}{ Variables } & \multicolumn{4}{|c|}{ Examining greater number of patients with $\mathrm{DH}$} \\
\hline & Crude OR (95\% CI) & $p$-Value & Adjusted OR (95\% Cl) & $p$-Value \\
\hline $\begin{array}{l}\text { Gender } \\
\text { Female } \\
\text { Male }\end{array}$ & $4.91(3.03,7.96)$ & $<0.001$ & $7.79(3.87,15.66)$ & $<0.001$ \\
\hline $\begin{array}{l}\text { Type of job } \\
\text { Private }^{a} \\
\text { Public }\end{array}$ & $4.96(3.06,8.05)$ & $<0.001$ & $7.34(3.78,14.25)$ & $<0.001$ \\
\hline $\begin{array}{l}\text { Monthly income } \\
<500 \text { \$US } \\
\geq 500 \text { \$US }\end{array}$ & $4.54(2.64,7.8)$ & $<0.001$ & $9.41(4.67,18.93)$ & $<0.001$ \\
\hline $\begin{array}{l}\text { Year since graduation } \\
>\text { Five years } \\
\leq \text { Five years }\end{array}$ & $0.86(00.56,1.32)$ & 0.498 & $2.75(1.46,5.19)$ & 0.002 \\
\hline $\begin{array}{l}\text { Basic dental qualification (BDS or equivalent) } \\
\text { obtained from } \\
\text { Private dental college } \\
\text { Public dental college }\end{array}$ & $4.72(2.91,7.65)$ & $<0.001$ & $2.04(1.09,3.82)$ & 0.026 \\
\hline
\end{tabular}

Abbreviations: $\mathrm{Cl}$, confidence interval; $\mathrm{DH}$, dentine hypersensitivity; OR, odds ratio.

aeference categories.

This is the first study that provided valuable data about the current trends of diagnosis and management of $\mathrm{DH}$ in dental practice in Pakistan. The analysis of a large data in the study provided robust and valid findings that can be used by the organizers of continuing education activities and dental institutions to enhance knowledge and skills of dental professionals related to $\mathrm{DH}$. Although data collection included a large sample of dentists from a cosmopolitan city of 11.1 million people, the generalizability of the results to other geographical locations or regions should be done with caution. In addition, the dentists conveniently participated in the study. Hence, the study may not comprehensively represent the dentists' population in the city. Moreover, there can be over- and under-reporting of some responses by male and female dentists, private and public dentists, and dentists with less or more clinical experience, etc. In future, a nationwide study should be conducted to evaluate practices of dentists about DH.

\section{Conclusion}

In conclusion, $\mathrm{DH}$ is a highly prevalent condition in dental practice. The majority of dentists identified recession of gums, aggressive brushing, and frequent use of tooth whitening procedures as the predisposing factors. Diagnostic techniques and management preferences varied among participating dentists. The application of air blast and spontaneous patient report confirmed by dental examination were the most frequently used diagnostic methods. Preferred management approaches included the use of fluoride products, desensitizing toothpastes, and bonding agents. Dental practitioners should continuously update their knowledge and skills to effectively manage $\mathrm{DH}$ and improve quality of life of patients.

\section{Conflict of Interest}

None declared.

\section{References}

1 Canadian Advisory Board on Dentin Hypersensitivity. Consensus-based recommendations for the diagnosis and management of dentin hypersensitivity. J Can Dent Assoc 2003;69(4):221-226

2 Kopycka-Kedzierawski DT, Meyerowitz C, Litaker MS, et al. National Dental PBRN Collaborative Group. Management of Dentin Hypersensitivity by National Dental Practice-Based Research Network practitioners: results from a questionnaire administered prior to initiation of a clinical study on this topic. BMC Oral Health 2017;17(1):41

3 Bekes K, John MT, Schaller HG, Hirsch C. Oral health-related quality of life in patients seeking care for dentin hypersensitivity. J Oral Rehabil 2009;36(1):45-51

4 Boiko OV, Baker SR, Gibson BJ, et al. Construction and validation of the quality of life measure for dentine hypersensitivity (DHEQ) J Clin Periodontol 2010;37(11):973-980

5 West NX, Sanz M, Lussi A, Bartlett D, Bouchard P, Bourgeois D. Prevalence of dentine hypersensitivity and study of associated factors: a European population-based cross-sectional study. J Dent 2013;41(10):841-851

6 Addy M. Tooth brushing, tooth wear and dentine hypersensitivity--are they associated? Int Dent J 2005;55(4, Suppl 1): 261-267

7 Costa RS, Rios FS, Moura MS, Jardim JJ, Maltz M, Haas AN. Prevalence and risk indicators of dentin hypersensitivity in adult and elderly populations from Porto Alegre, Brazil. J Periodontol 2014;85(9):1247-1258

8 Que K, Ruan J, Fan X, Liang X, Hu D. A multi-centre and cross-sectional study of dentine hypersensitivity in China. J Clin Periodontol 2010;37(7):631-637

9 Ye W, Feng XP, Li R. The prevalence of dentine hypersensitivity in Chinese adults. J Oral Rehabil 2012;39(3):182-187

10 Haneet RK, Vandana LK. Prevalence of dentinal hypersensitivity and study of associated factors: a cross-sectional 
study based on the general dental population of Davangere, Karnataka, India. Int Dent J 2016;66(1):49-57

11 Bamise CT, Olusile AO, Oginni AO, Dosumu OO. The prevalence of dentine hypersensitivity among adult patients attending a Nigerian teaching hospital. Oral Health Prev Dent 2007;5(1):49-53

12 Gillam DG, Bulman JS, Eijkman MA, Newman HN. Dentists' perceptions of dentine hypersensitivity and knowledge of its treatment. J Oral Rehabil 2002;29(3):219-225

13 Amarasena N, Spencer J, Ou Y, Brennan D. Dentine hypersensitivity - Australian dentists' perspective. Aust Dent J 2010;55(2):181-187

14 Kopycka-Kedzierawski DT, Meyerowitz C, Litaker MS, et al. National Dental PBRN Collaborative Group. Management of dentin hypersensitivity by practitioners in The National Dental Practice-Based Research Network. J Am Dent Assoc 2017;148(10):728-736

15 Afolabi AO, Ogundipe OK, Adegbulugbe IC, Shaba OP. Perception of dentine hypersensitivity and its management by a group of Nigerian dentists. Nig Q J Hosp Med 2012;22(3):216-220

16 Oderinu OH, Sede MA, Oginni AO, et al. Knowledge, diagnosis and management of dentine hypersensitivity: a national survey of dentists in Nigeria. Int Dent J 2017;67(5):287-293

17 Sullivan KM. Documentation for Sample Size for a Proportion. Available at: https://www.openepi.com/PDFDocs/SSCohortDoc. pdf. Accessed August 12, 2017

18 Stojsin I, Petrović L, Stojanac I, Drobac M. Multi-factoriality of dentine hypersensitivity [Article in Serbian]. Med Pregl 2008;61(7)(8):359-363

19 Pereira R, Gillam D, Bapatla S, Satyamurthy P. Awareness of dentine hypersensitivity among general dental practitioners in Mumbai, India. J Odontol 2018;2:103
20 Cunha-Cruz J, Wataha JC, Zhou L, et al. Treating dentin hypersensitivity: therapeutic choices made by dentists of the northwest PRECEDENT network. J Am Dent Assoc 2010;141(9):1097-1105

21 Benoist FL, Ndiaye FG, Faye B, Bane K, Ngom PI, Ndong PM. Knowledge of and management attitude regarding dentin hypersensitivity among dentists from a West African country. J Contemp Dent Pract 2014;15(1):86-91

22 Clark D, Levin L. Tooth hypersensitivity treatment trends among dental professionals. Quintessence Int 2018;49(2):147-151

23 Heft MW, Litaker MS, Kopycka-Kedzierawski DT, et al. National Dental PBRN Collaborative Group. Patient-centered dentinal hypersensitivity treatment outcomes: results from the national dental PBRN. JDR Clin Trans Res 2018;3(1):76-82

24 Lamont T, Innes N. Study suggests dentine bonding agents provided better relief from dentine hypersensitivity than a desensitising toothpaste. Evid Based Dent 2013;14(4):105-106

25 Yilmaz HG, Kurtulmus-Yilmaz S, Cengiz E. Long-term effect of diode laser irradiation compared to sodium fluoride varnish in the treatment of dentine hypersensitivity in periodontal maintenance patients: a randomized controlled clinical study. Photomed Laser Surg 2011;29(11):721-725

26 Umberto R, Claudia R, Gaspare P, Gianluca T, Alessandro V. Treatment of dentine hypersensitivity by diode laser: a clinical study. Int J Dent 2012;2012:858950

27 Hashim NT, Gasmalla BG, Sabahelkheir AH, Awooda AM. Effect of the clinical application of the diode laser $(810 \mathrm{~nm})$ in the treatment of dentine hypersensitivity. BMC Res Notes 2014;7:31 